\title{
Virtualisation devices for student learning: Comparison between desktop-based (Oculus Rift) and mobile-based (Gear VR) virtual reality in medical and health science education
}

\author{
Christian Moro, Zane Stromberga, Allan Stirling \\ Bond University
}

\begin{abstract}
Consumer-grade virtual reality has recently become available for both desktop and mobile platforms and may redefine the way that students learn. However, the decision regarding which device to utilise within a curriculum is unclear. Desktop-based VR has considerably higher setup costs involved, whereas mobile-based VR cannot produce the quality of environment due to its limited processing power. This study aimed to compare performance in an anatomical knowledge test between two virtual reality headsets, the Oculus Rift and Gear VR, as well as to investigate student perceptions and adverse health effects experienced from their use. An identical lesson on spine anatomy was presented to subjects using either the Oculus Rift or Gear VR, with no significant differences observed in test scores from participants using either device, with both groups answering $60 \%$ of the questions correctly. However, $40 \%$ of participants experienced significantly higher rates of nausea and blurred vision when using the Gear VR $(P<0.05)$. It was established that the more cost effective mobile-based VR was just as suitable for teaching isolated-systems than the more expensive desktop-based VR. These outcomes show great promise for the effective use of mobile-based virtual reality devices in medical and health science education.
\end{abstract}

\section{Introduction}

Over the past 12 months many new consumer-grade virtual reality (VR) devices have been released to the public. These promise to revolutionise the way we view, perceive, and experience media. Aside from the applications in gaming, interest has been growing in the use of this technology in education. VR provides opportunities to navigate 3D models and environments, in a way that allows students to view learning experiences from an entirely new perspective (Moro, Stromberga, Raikos, \& Stirling, 2017). This is particularly important in health sciences and medical education, where a clear knowledge of anatomy constitutes a major component of student learning in these courses. The first consumer-grade desktop device to be released was the Oculus Rift, although the uptake of this device in education has been limited largely due to the high setup costs involved. At the same time however, newer mobile devices, such as Google Cardboard ( $\sim 20$ USD) or the Gear VR ( \$99 USD), also now have the capacity to depict virtual reality with attachments. These devices have a great difference in the cost of setup for educational institutions, and could potentially utilise the students own mobile phones in the future as more and more devices become VR-compatible.

Learning is a process of acquiring knowledge that results in the ability to do or understand concepts and tasks that were not previously understood. Effective learning consists of three components: motivation to learn, clear goals, and adequate use in practice (Dale, 1946). By satisfying these three conditions, education can become a rich and engaging experience. Contemporary teaching and learning is slowly moving away from the traditional classroom setting and into an online environment, which also entails computergenerated 3D models (Guarino et al., 2014). Educators continuously seek ways to improve the learning outcomes of their students and help them master the content more readily. Advancements in hardware and software technology have provided new possibilities to create interactive learning tools that are not constrained by time or physical location (Chittaro \& Ranon, 2007). In the past, 3D interactive software has seldom been utilised in the classroom setting, in part due to limitations in computing power, affordability, or educators not being familiar with this type of technology (Dunleavy, Dede, \& Mitchell, 2008). With recent advancements in technology these limitations are largely resolved, creating new educational opportunities in anatomical science (Trelease, 2016). There have been several attempts to teach anatomy using 3D interactive software. Whilst the models developed for these studies were anatomically accurate, they did not clearly represent the visual and aesthetic qualities of the structures. There are reports of models 
that have been developed using CT (Keedy et al., 2011; Wang, Xue, Jing, \& Wang, 2012) and MRI scans (Hu, Wilson, Ladak, Haase, \& Fung, 2009; Kockro et al., 2015; Metzler et al., 2012; Nguyen, Nelson, \& Wilson, 2012; Nicholson, Chalk, Funnell, \& Daniel, 2006; Wang et al., 2012). However, very few studies have been able to create both accurate and photorealistic anatomy models. One such example is the Falah et al. (2015) model of the heart. This group not only used CT scans, but also photographic material, X-rays, ultrasound and 2D images to create a realistic 3D model. It is important to note that this study found the 3D learning environment to be superior to the traditional teaching methods by finding a significant increase in the mean test scores for the group that used the model. Therefore, it can be said that 3D models used in medical education should not only be anatomically accurate, but also visually pleasing and realistic, to assist the learner when engaging with the study material (Roth, Wilson, \& Sandig, 2015). Hence, the utilisations of older, less powerful software and models raises the question of the viability of older studies in this area as the most prominent improvements in digital display technology have only been introduced over the past two years. Although this may suggest that previous studies can be unreliable, they have provided substantial longitudinal insights into student learning in digital environments as technology developed.

When introducing new learning tools for use in a classroom setting, it is also important to take into consideration the attitude of educators towards the implementation of technology. Despite the good intentions of the emerging technology, teaching staff may be reluctant to include them in their teaching due to the perception of them being a "waste of time", or as a "too radical change" from traditional methods, or simply due to their lack of familiarity with the new technology (Chittaro \& Ranon, 2007). Additionally, Dunleavy et al. (2008) found that teachers were uncomfortable integrating the new technology in lessons because they no longer had control of what students were doing and whether they were fulfilling the given task. However, insights in cognitive psychology can help educators make informed decisions on how to make learning material in a way that enhances learner's capacity to remember more concepts by minimising the load on the working memory (Mayer, 2009). Learning without the use of interactive software requires more cognitive effort to be put in synthesis of knowledge, as the information has to be integrated from various sources, imposing high demand on the available cognitive resources (Chen, 2006; Sweller, Van Merrienboer, \& Paas, 1998). The right instructional approach will foster cognitive processes during learning, guiding students to select, organise and integrate relevant knowledge (Mayer, 2008). Splitattention effect occurs when the same modality is used to present information (e.g., only visual information: image and text) (Sweller et al., 1998). In order to counter this effect and reduce the load on working memory, both visual and textual information, supported by a narration, should be integrated in the learning tool. An example of this instructional design is the $\mathrm{Hu}$ et al. (2009) study that created a lesson on the anatomy of the larynx using the 3D model of the structure, accompanied by written and auditory information.

It is known that students are more likely to learn the study material when the mode of teaching matches their individually preferred mode of learning (Curry, 1981), with $40 \%$ of students learning best when the presented tool is multimodal (Fleming, 2006). Lujan and DiCarlo (2006) also supported this, with more than half of the surveyed medical students preferring it when information was presented using multiple modes. As stated by Mayer (2008), people encode information more efficiently when narrations and animations are presented at the same time rather than one after the other, as well as images or graphs with spoken text rather than written text. Based on previous research (Mayer \& Moreno, 2002) presenting interactive images or in conjunction with auditory narrations provided more beneficial learning experiences. Using this method to learn also leads students to pay more attention to concepts being taught hence reducing the odds of them getting distracted. It may also assist undergraduate medical students, who tend to require a greater degree of support within a medical program than their postgraduate counterparts (Moro \& McLean, 2017). Therefore, the use of virtual reality to supplement lecture material builds upon these research recommendations, and has the potential to greatly help students learn in their preferred style. For example, when learning from an interactive 3D model, students can explore different angles of the model and identify complex anatomical structures more effectively than only with traditional methods (Chien, Chen, \& Jeng, 2010).

The key element of a good pedagogy practice, irrespective of the teaching method used, is interaction (Woo \& Reeves, 2007). The Cone of Experience devised by Dale (1946) explains the relationship of different sensory material used in learning, moving from direct experience to abstract type of learning. Direct experience is considered to be most effective type of experiential learning, followed by contrived 
experiences (Dale, 1946). Based on this principle, it can be presumed that learning in a virtual environment would be a type of contrived experience simulated in a virtual world where the user is actively performing tasks and essentially learning by doing. However, based on the results from previous studies (Azer \& Azer, 2016; Berney, Betrancourt, Molinari, \& Hoyek, 2015; Codd \& Choudhury, 2011; Hu et al., 2009; Keedy et al., 2011; Kockro et al., 2015) there was no significant improvement in the results of students that studied anatomy in 3D environment in comparison to a 2D environment. The reason for these results could be either due to the lack of realism to simulate a contrived experience or due to a poor anatomical model. With regards to the realism of the experience, $\mathrm{Ng}$, Liu, Chee, and Ngo (2015) study found that even a simplified 3D geometrical model of the middle ear was regarded as a more effective learning tool by the students that participated in that study. Perhaps this type of model is more applicable in this learning environment where the structure of the ear is too small to be properly examined in real life and contains too many small details that would be better represented in a virtual environment with the use of geometrical shapes. When an educational intervention is poorly designed and delivered, it can lead to misinterpretation or inconclusive results (Curry, 1981). Therefore, when creating learning tools, special attention needs to be paid not only to the anatomical accuracy but also to instructional design in software development.

\section{Purpose of the study}

The beginnings of modern-day virtual reality can be traced back to 2012, when a kickstarter project named Oculus Rift was introduced, promising to provide high quality head-mounted displays that could mimic the real world (Anthes, García-Hernandez, Wiedemann, \& Kranzlmüller, 2016). In 2016, after the release of two developer kits Oculus Rift DK1 and DK2, the first consumer-grade Oculus Rift CV1 became available for the general public (Oculus, 2016). Another VR device that has only been recently released is the Gear VR by Samsung and powered by Oculus (Oculus, 2015). In comparison to Oculus Rift, this device is wireless and solely relies on the technology of a smartphone to create an immersive virtual experience (Anthes et al., 2016). Previous applications of Oculus Rift in education include the creation of a virtual lecture presented by a virtual instructor where it was found that students performed better in the knowledge quiz administrated after the lecture in comparison to those that watched a recording of the lecture (Tsaramirsis et al., 2016), virtual exploration of archaeological sites (Borba, Cabral, Lopes, Zuffo, \& Kopper, 2016), or virtual anatomical visualisations (Moro et al., 2017). Since this technology is still recent, there are only a limited number of studies that have utilised modern-day virtual reality devices in medical education. Examples of virtual reality application in medical education: a 3D virtual anatomy puzzle using Oculus Rift DK2 (Messier, Wilcox, Dawson-Elli, Diaz, \& Linte, 2016). Other current applications of virtual reality that are being investigated include creating virtual classrooms through use of Oculus Rift where the student is able to interact with a virtual instructor in a virtual lecture (Tsaramirsis et al., 2016). In comparison to traditional multimedia tools, this learning environment makes the student feel as if they are really present in the lecture theatre. Therefore, the release of modern virtual reality systems has paved the way for new approaches to medical imaging and education. To our knowledge, there are no current studies evaluating the learning outcomes of students who use modern virtual reality devices, such as Oculus Rift and Gear VR. This study aimed to compare performance in an anatomical knowledge test between two virtual reality headsets, the Oculus Rift and Gear VR, as well as investigate student perceptions and adverse health effects exhibited during the lesson.

Modern-day virtual reality has expanded the capabilities of technology enhanced learning as these systems become more accessible to universities. The pedagogical motivation to create educational resources to be utilised in virtual reality is based on the constructivist learning theory as it can be applied to new technologies. It states that individuals learn through meaningful experiences where the user actively constructs their knowledge by engaging in specific tasks (Conceição-Runlee \& Daley, 1998). Therefore, the highly interactive and immersive nature of a virtual environment can provide a substitute for real life experience where knowledge is constructed by direct experience (Limniou, Roberts, \& Papadopoulos, 2008). It has been hypothesised that virtual learning environment will increase student practice time, leading to better understanding and improved learning outcomes (Brewer, Wilson, Eagleson, \& de Ribaupierre, 2012; Moro et al., 2017). Research in the use of these devices is still in its infancy along with recommendations for developing instructional software to be used on them. Therefore, it is of importance to explore multimedia learning tool design specifically for use on the modern $3 \mathrm{D}$ visualisation devices. 


\section{Methodology}

\section{Development of the application}

The applications for Gear VR and Oculus Rift CV1 were written using JavaScript within Unity v5 (Unity Technologies, San Francisco, California, USA). The model of the spine was purchased form TurboSquid (turbosquid.com, New Orleans, Louisiana, USA) and edited, colourised and assessed for accuracy and visibility in the virtual environment. The Oculus Rift CV1 devices were run on an Alienware Area 51 with a CORE i7-5820 CPU @ 3.30GHz, 16GB RAM (Dell Inc. Round Rock, TX, USA) and GTX980ti GPU (nVidia, Santa Clara, CA, USA) with Windows 10 x64 operating system. The Gear VR was attached to Samsung S7 Edge devices. Control of the model was completed using a handheld Bluetooth-connected Moga Pro Power controller (Bensussen Deutsch and Associates Inc, WA, USA).

\section{Research design}

Twenty participants were allocated to one of the two virtual reality modes to complete a lesson on the anatomy of the spine (Figure 1), with randomisation performed through https://www.random.org/ (Randomness and Integrity Services Ltd., Dublin, Ireland). The time allocated for each participant was approximately 30 minutes. All recruited participants completed the study and no data was withdrawn. Prior to commencement, participants were asked to read an explanatory statement and provide informed consent. Participants initially filled out an online survey to gather demographic data and completed a multiple-choice question pre-test to assess their baseline knowledge of spinal anatomy. Both groups then received a lesson on the virtual reality devices, containing a computerised 3D model of the spine and a 10 -minute podcast narrated by a specialist surgeon.

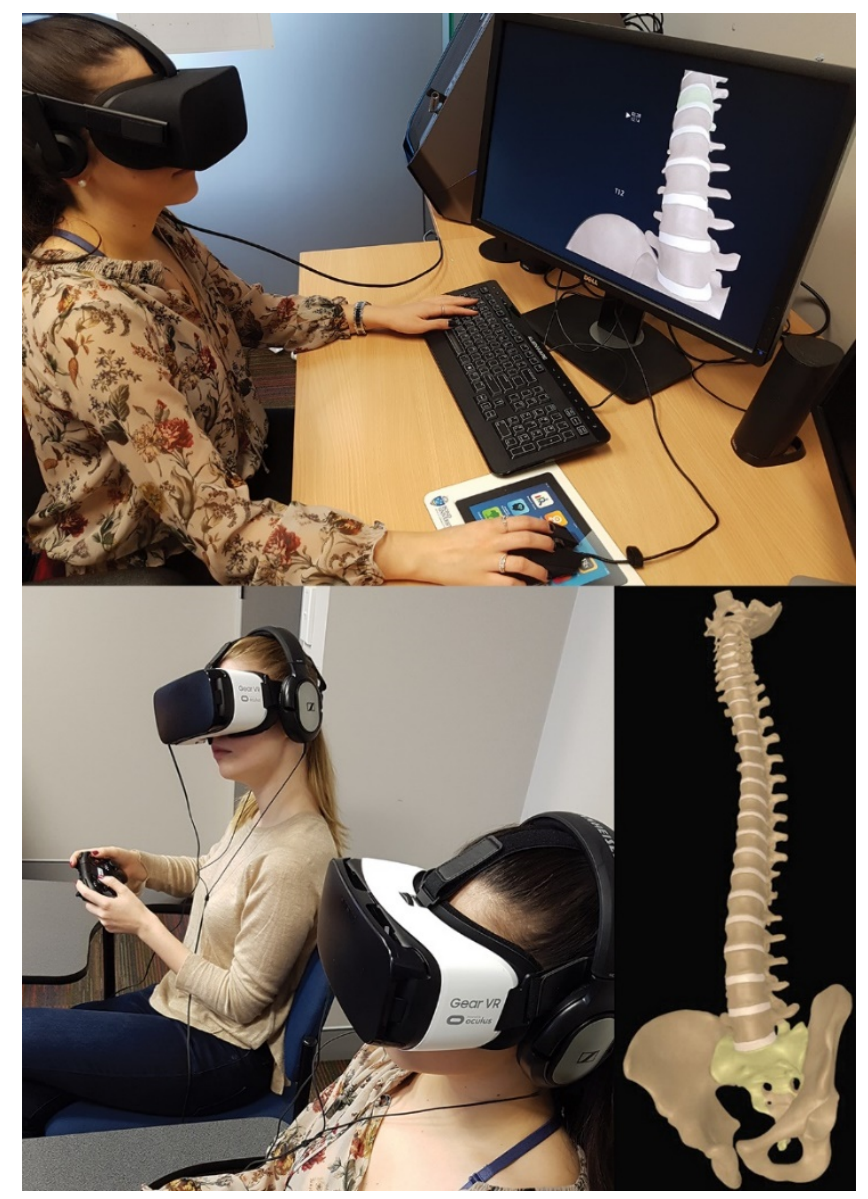

Figure 1. Upper image: Subject navigating the spine while utilising the application on the Oculus Rift. Lower Left Image: Subjects engaging in the lesson on the Gear VR devices. Lower Right Image: The model of the spine utilised in both the Oculus Rift and Gear VR devices. 
As the different parts of the spine were introduced during the podcast, the structure of interest was highlighted in blue to guide the viewer. Participants could manipulate the model using a Bluetooth wireless controller, and could navigate within the structure, around the model, and remove or replace layers of the model to view underlying features.

After the lesson, participants filled out the second half of the questionnaire, which consisted of Likert-style questions regarding the adverse health effects experienced during the lesson and participant engagement with the learning module. The last part of the questionnaire was a multiple-choice question anatomy test, which evaluated the transfer of the knowledge. To compare the health effects reported during the lesson on spine anatomy in two virtual reality environments (Oculus Rift and Gear VR), an online questionnaire was created using Qualtrics (qualtrics.com). Ethics was approved by the Bond University Human ethics committee and all participants provided informed consent.

\section{Data analysis}

A Student's $t$-test was used to evaluate the association between the virtual reality device (Oculus Rift or Gear VR) and the anatomy test scores. A Mann-Whitney U-test was used to evaluate the association between virtual reality devices and the adverse health effects experienced during the lesson, as well as participant perception of the learning mode. The adverse health effects were rated on a 4-point Likert scale ( 1 = none to 4 = severe $)$, where lower scores indicated less symptoms experienced. Participant perceptions were rated on a 5-point Likert scale ( 1 = strongly disagree to 5 = strongly agree), where lower scores would indicate negative perception about the learning mode, and higher scores would indicate a positive perception. No qualitative data was gathered in this study.

\section{Results}

\section{Participant data}

Participants were split into two groups where each group was provided with a lesson presented in either virtual reality on Oculus Rift or on Gear VR. The main demographic data of this study is represented in Table 1. All 20 participants recruited were students of Faculty of Health Sciences and Medicine at Bond University with 19 subjects studying health sciences and one participant being a postgraduate student (Table 1). The gender was distributed equally $-50 \%$ males and $50 \%$ females. The mean participant age was 19.8 years old, with ages ranging from 17 to 28. Through the process of randomisation, 10 participants were allocated to the Oculus Rift group and 10 to the Gear VR group. A quarter of the participants (25\%) had studied science since leaving high school at institutes such as TAFE and university. Most (65\%) participants had no previous experience using either of the VR systems prior to this study. 20\% participants had used computerised 3D models, $5 \%$ had used virtual reality and 25\% had used augmented reality as a means of learning anatomy. The majority (95\%) of participants reported that they sometimes have difficulties understanding the position of an anatomical structure in 3D space. Two-fifths (40\%) of subjects required prescription glasses for either short-sightedness or long-sightedness.

Table 1

Participant demographic data

\begin{tabular}{lccc}
\hline & $\begin{array}{c}\text { Oculus Rift } \\
(n=10)\end{array}$ & $\begin{array}{c}\text { Gear VR } \\
(n=10)\end{array}$ & $\begin{array}{c}\text { Total } \\
(N=20)\end{array}$ \\
\hline Education & & & 19 \\
$\quad$ Health sciences & 10 & 9 & 1 \\
$\quad$ Postgraduate & 0 & 1 & $50 \%(10)$ \\
Male & $50 \%(4)$ & $50 \%(4)$ & $50 \%(10)$ \\
Female & $50 \%(6)$ & $20.5 \pm 3.5$ & $19.80 \pm 2.9$ \\
Age (mean $\pm S D)$ & $19.1 \pm 2.1$ & $40 \%(4)$ & $25 \%(5)$ \\
Science background & $10 \%(1)$ & & \\
\hline
\end{tabular}




\section{Anatomical knowledge test scores}

Prior to the anatomy lesson participants were given a 5-question pre-test paper. Here the Oculus Rift group received a mean score of $40 \%$ and Gear VR group $66 \%$. The difference in the test scores between the two groups was found to be significant $(p=0.01)$, however this has no effect on the 12-question anatomical knowledge test scores administrated straight after the lesson, where both groups received a mean score of $60 \%$ (Table 2).

Table 2

Mean anatomical quiz scores (in percentages) for participants in Oculus Rift and Gear VR groups

\begin{tabular}{lccc} 
& Oculus Rift & Gear VR & $p$ value \\
\hline Pre-test & $40 \%$ & $66 \%$ & $0.01^{*}$ \\
Anatomical knowledge test & $60 \%$ & $60 \%$ & 1.000 \\
\hline
\end{tabular}

Independent sample $T$ test: ${ }^{*} p<0.05$

Adverse health effects experienced during the lesson

Participant reports on adverse health effects experienced during the lesson were evaluated using a 4-point Likert scale, where they were asked to rate their symptoms as none, slight, moderate, or severe. Both virtual reality systems resulted in similar symptom experiences during the lesson however the participants in Gear VR group experienced a significant increase in the severity of two symptoms: disorientation and blurred vision $(p=0.029$, Table 3$)$.

Table 3

Percentage of students that exhibited adverse symptoms during the spine anatomy lesson on Gear VR and Oculus Rift devices

\begin{tabular}{lccc}
\hline \multicolumn{1}{c}{ General Symptoms } & Oculus Rift & Gear VR & $p$ value \\
\hline General discomfort & $0 \%$ & $20 \%$ & 0.146 \\
Fatigue & $10 \%$ & $10 \%$ & 1.000 \\
Boredom & $10 \%$ & $20 \%$ & 0.542 \\
Drowsiness & $30 \%$ & $20 \%$ & 0.615 \\
Headache & $10 \%$ & $10 \%$ & 1.000 \\
Dizziness & $0 \%$ & $10 \%$ & 0.317 \\
Difficulty concentrating & $10 \%$ & $30 \%$ & 0.255 \\
Nausea & $10 \%$ & $10 \%$ & 1.000 \\
Disorientation & $0 \%$ & $40 \%$ & $0.029^{*}$ \\
\hline \multicolumn{1}{c}{ Eye-related symptoms } & & & 1.000 \\
\hline Tired eyes & $20 \%$ & $20 \%$ & 0.067 \\
Sore/aching eyes & $0 \%$ & $30 \%$ & 0.146 \\
Eyestrain & $0 \%$ & $20 \%$ & $0.029 *$ \\
Blurred vision & $0 \%$ & $40 \%$ & 0.121 \\
Difficulty focusing & $10 \%$ & $40 \%$ & 0.146 \\
Double-vision & $0 \%$ & $20 \%$ & \\
\hline
\end{tabular}

Mann-Whitney U test: ${ }^{*} p<0.05$

Participant engagement with the learning mode

Participants rated their learning experience highly in all 7 domains across both groups. The differences in responses were determined using the mean values obtained from a 5-point Likert scale $(1=$ strongly disagree, 2 = disagree, 3 = neutral, 4 = agree and $5=$ strongly agree) in response to the given statements. There were no significant differences observed for any of the seven statements describing perceptions of the learning activities between the two groups. Significantly more participants selected strongly agree when rating the user-friendliness $(p=0.024)$, instructions and labels $(p=0.007)$ and comfort using the module $(p=0.012$, Figure 2). 
$\square$ Oculus Rift $\quad$ Gear VR

I enjoyed learning anatomy using this module

This provided useful supplementary material

It is easy to understand anatomy using this module

It is an effective learning tool

The software is user friendly

The instructions and labels were clear

I felt comfortable using this module

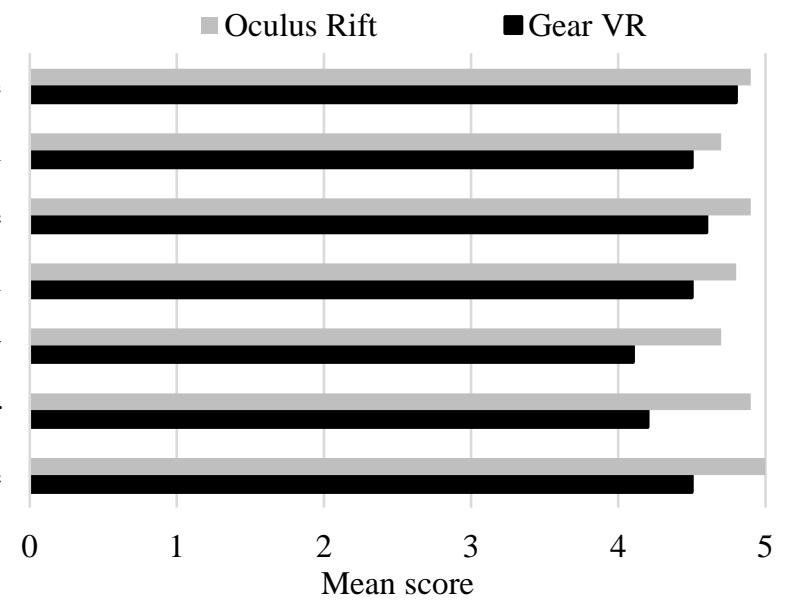

Figure 2. Participant perception of learning the anatomy of the spine when using Oculus Rift and Gear VR

\section{Discussion}

\section{General perception of VR delivery}

A common theme regarding learning is to find ways to make it more interesting and fun. Once the student enjoys the learning mode and perceives it as an enjoyable activity rather than a laborious task, they are more inclined to follow it through to the end. Studies have reported that learning material that is delivered in an exciting manner can cause the learner to retain more knowledge and also engage in the concepts (Pascarella, 2006). In our study, when compared to traditional lecture-style learning, participants perceived the VR lesson as more engaging and fun. However, they did acknowledge the importance of lectures and having only the VR devices available for study may have not been suitable to gain a full understanding of the required anatomical concepts. Both virtual reality devices were regarded as great supplementary tools to lectures that make the learning process more fun. A combination of both, lectures, cadaveric laboratories and virtual reality devices, was regarded as the most preferred method of learning anatomical structures offering a more holistic approach to learning complex structural anatomy.

The VR lessons showed high levels of student enjoyment and perceived usefulness of the learning tool. Based upon results, student enjoyment in the VR group was not influenced by the number of adverse health effects experienced. These findings are also consistent with the von Mammen, Knote, and Edenhofer (2016) and Moro et al. (2017) results, where participants experienced cybersickness but still had high satisfaction ratings and were willing to use Oculus Rift again. In our study, when comparing between the two VR systems (Oculus Rift and Gear VR), participant experiences were rated above 4 out of 5 in all 7 domains, with higher scores obtained within the Oculus Rift group. The increased preference for virtual reality using Oculus Rift instead of Gear VR could also be possibly due to the controllers. Oculus Rift, being run using a computer, utilised a mouse whereas Gear VR used a Bluetooth controller to interact with the model. As also found in this study, significantly larger portion of people experienced disorientation when using Gear VR in comparison to Oculus Rift, which may have also been due to the use of a controller. As determined based upon student feedback, the controller was also perceived to be harder to use than the computer mouse. A detailed investigation into the best use of controllers, or a mouse and keyboard combination for navigation through the virtual environment in the future, may further assist educators and curriculum developers wishing to incorporate the Gear VR into their student education.

\section{Adverse health effects}

A potential issue that can have an impact on the learning experience when using virtual reality is cybersickness, and can present as nausea, disorientation, discomfort, headache fatigue, difficulty concentrating and problems with vision (Settgast, Pirker, Lontschar, Maggale, \& Gütl, 2016). It is a result of sensory mismatch, occurring when the visual system tells the body that is moving whilst the vestibular system tells the body it is stationary (Howarth \& Costello, 1997). A study that investigated cybersickness in participants that played a first-person shooting game on DK1 Oculus Rift found that most participants 
experienced cybersickness, rating it 8 out of 10 (Tan, Leong, Shen, Dubravs, \& Si, 2015). In other similar studies, participants also experienced various degrees of symptoms associated with cybersickness, however it did not take away from their experience and all participants still enjoyed the VR experience (Moro et al., 2017; Settgast et al., 2016; von Mammen et al., 2016). In this study, participants experienced significantly more symptoms in the Gear VR than the Oculus Rift. The general symptoms exhibited (general discomfort, headache, dizziness, nausea and disorientation) are consistent with the symptoms caused by cybersickness with the use of head-mounted displays (Moro et al., 2017; Rebenitsch \& Owen, 2016). Both general nausea and blurred vision were significantly higher in the Gear VR, which is a worrying as experiencing these symptoms would likely have a great impact on the learning quality and make the student less immersed in the lesson. One-third of VR group experienced blurred vision and difficulty concentrating, whereas doublevision was present in $21 \%$ of participants. This increase in symptoms is also consistent with cybersickness reported when using the Oculus Rift (Davis, Nesbitt, \& Nalivaiko, 2014; Moro et al., 2017). General discomfort was not reported by any of the Oculus Rift participant, although was reported in $20 \%$ of Gear VR participants. Dizziness was also present in 10\% of Gear VR participants. Overall, participants in the Oculus Rift group experienced significantly less symptoms than the Gear VR group with only a few reports of having experienced any of the other adverse health effects.

A surprising report was the prevalence of blurred vision in Gear VR users. It is unclear why this occurred in nearly half (40\%) of the Gear VR users, although positioning on the face or a lack of experience with the focus-dial may account for this. The Gear VR goggles have a built-in rotating disc that the participant could regulate to increase the sharpness of the image, whereas the Oculus Rift does not have this feature. Based on this, with further practice and use, participants should become better at making the experience clearer and reducing blurred vision. Even though all participants were trained on this process, it is possible that it was missed by some, leading to a blurred experience. It is also possible that the limited computing power or reduced frame-rates of the smartphones when compared with the more advanced visualisations on the Oculus Rift resulted in structures or text appearing blurry on the mobile device.

\section{Conclusion}

Virtual reality is an effective method to supplement lessons in anatomy for students studying health sciences and medicine. Mobile-based virtual reality is as effective as desktop-based virtual reality, and requires a substantially lower cost for setup. However, shorter lessons in the virtual environment are required, as mobile virtual reality lessons can cause more cybersickness and adverse effects than desktop-based applications.

\section{References}

Anthes, C., García-Hernandez, R. J., Wiedemann, M., \& Kranzlmüller, D. (2016, March). State of the art of virtual reality technology. Paper presented at the 2016 IEEE Aerospace Conference, Yellowstone, MT.

Azer, S. A., \& Azer, S. (2016). 3D anatomy models and impact on learning: A review of the quality of the literature. Health Professions Education, 2(2), 80-98. https://doi.org/10.1016/j.hpe.2016.05.002

Berney, S., Betrancourt, M., Molinari, G., \& Hoyek, N. (2015). How spatial abilities and dynamic visualizations interplay when learning functional anatomy with 3D anatomical models. Anatomical Sciences Education, 8(5), 452-462. https://doi.org/10.1002/ase.1524

Borba, E. Z., Cabral, M., Lopes, R. d. D., Zuffo, M. K., \& Kopper, R. (2016, March). A fully immersive virtual model to explore archaeological sites. Paper presented at the 2016 IEEE Virtual Reality (VR), Yellowstone, MT.

Brewer, D. N., Wilson, T. D., Eagleson, R., \& de Ribaupierre, S. (2012). Evaluation of neuroanatomical training using a 3D visual reality model. Studies in Health Technology and Informatics, 173, 85-91.

Chen, C. J. (2006). The design, development and evaluation of a virtual reality based learning environment. Australasian Journal of Educational Technology, 22(1), 39-63.

Chien, C.-H., Chen, C.-H., \& Jeng, T.-S. (2010, March). An interactive augmented reality system for learning anatomy structure. Paper presented at the the International MultiConference of Engineers and Computer Scientists, Hong Kong.

Chittaro, L., \& Ranon, R. (2007). Web3D technologies in learning, education and training: Motivations, issues, opportunities. Computers \& Education, 49(1), 3-18.

https://dx.doi.org/10.1016/j.compedu.2005.06.002 
Codd, A. M., \& Choudhury, B. (2011). Virtual reality anatomy: Is it comparable with traditional methods in the teaching of human forearm musculoskeletal anatomy? Anatomical Sciences Education, 4(3), 119-125. https://doi.org/10.1002/ase.214

Conceição-Runlee, S., \& Daley, B. J. (1998, October). Constructivist learning theory to web-based course design: An instructional design approach. Paper presented at the Midwest Research to Practice Conference, Muncie, IN.

Curry, L. (1981). Learning preferences and continuing medical education. Canadian Medical Association journal, 124(5), 535-536.

Dale, E. (1946). Audio-visual methods in teaching. New York, NY: Dryden Press.

Davis, S., Nesbitt, K., \& Nalivaiko, E. (2014, December). A systematic review of cybersickness. Paper presented at the 2014 Conference on Interactive Entertainment, Newcastle.

Dunleavy, M., Dede, C., \& Mitchell, R. (2008). Affordances and limitations of immersive participatory augmented reality simulations for teaching and learning. Journal of Science Education and Technology, 18(1), 7-22. https://doi.org/10.1007/s10956-008-9119-1

Falah, J., Charissis, V., Khan, S., Chan, W., Alfalah, S. F. M., \& Harrison, D. K. (2015). Development and evaluation of virtual reality medical training system for anatomy education. In K. Arai, S. Kapoor, \& R. Bhatia (Eds.), Intelligent systems in science and information 2014: Extended and selected results from the Science and Information Conference 2014 (pp. 369-383). Cham: Springer International Publishing.

Fleming, N. D. (2006). Teaching and learning styles: VARK Strategies. Christchurch: N.D. Fleming.

Guarino, S., Leopardi, E., Sorrenti, S., De Antoni, E., Catania, A., \& Alagaratnam, S. (2014). Internetbased versus traditional teaching and learning methods. Clin Teach, 11(6), 449-453. https://doi.org/10.1111/tct.12191

Howarth, P. A., \& Costello, P. J. (1997). The occurrence of virtual simulation sickness symptoms when an HMD was used as a personal viewing system. Displays, 18(2), 107-116. https://doi.org/10.1016/S0141-9382(97)00011-5

Hu, A., Wilson, T., Ladak, H., Haase, P., \& Fung, K. (2009). Three-dimensional educational computer model of the larynx: voicing a new direction. Archives of Otolaryngology-Head \& Neck Surgery, 135(7), 677-681. https://doi.org/10.1001/archoto.2009.68

Keedy, A. W., Durack, J. C., Sandhu, P., Chen, E. M., O'Sullivan, P. S., \& Breiman, R. S. (2011). Comparison of traditional methods with 3D computer models in the instruction of hepatobiliary anatomy. Anat Sci Educ, 4(2), 84-91. https://doi.org/10.1002/ase.212

Kockro, R. A., Amaxopoulou, C., Killeen, T., Wagner, W., Reisch, R., Schwandt, E., ... Stadie, A. T. (2015). Stereoscopic neuroanatomy lectures using a three-dimensional virtual reality environment. Annals of Anatomy - Anatomischer Anzeiger, 201, 91-98. https://doi.org/http://dx.doi.org/10.1016/j.aanat.2015.05.006

Limniou, M., Roberts, D., \& Papadopoulos, N. (2008). Full immersive virtual environment CAVETM in chemistry education. Computers \& Education, 51(2), 584-593. https://doi.org/10.1016/j.compedu.2007.06.014

Lujan, H. L., \& DiCarlo, S. E. (2006). First-year medical students prefer multiple learning styles. Advances in Physiology Education, 30(1), 13-16. https://doi.org/10.1152/advan.00045.2005

Mayer, R. E. (2008). Applying the science of learning: Evidence-based principles for the design of multimedia instruction. American Psychologist, 63(8), 760-769. https://doi.org/10.1037/0003066x.63.8.760

Mayer, R. E. (2009). Multimedia Learning. New York, NY: Cambridge University Press.

Mayer, R. E., \& Moreno, R. (2002). Animation as an aid to multimedia learning. Educational Psychology Review, 14(1), 87-99. https://doi.org/10.1023/a:1013184611077

Messier, E., Wilcox, J., Dawson-Elli, A., Diaz, G., \& Linte, C. A. (2016). An interactive 3D virtual anatomy puzzle for learning and simulation - initial demonstration and evaluation. Studies in Health Technology and Informatics, 220, 233-240.

Metzler, R., Stein, D., Tetzlaff, R., Bruckner, T., Meinzer, H. P., Buchler, M. W., . . Fischer, L. (2012). Teaching on three-dimensional presentation does not improve the understanding of according CT images: a randomized controlled study. Teaching and Learning in Medicine, 24(2), 140-148. https://doi.org/10.1080/10401334.2012.664963

Moro, C., \& McLean, M. (2017). Supporting students' transition to university and problem-based learning. Medical Science Educator, 27(2), 353-361. https://doi.org/10.1007/s40670-017-0384-6 
Moro, C., Stromberga, Z., Raikos, A., \& Stirling, A. (2017). The effectiveness of virtual and augmented reality in health sciences and medical anatomy. Anatomical Sciences Education. 10(6), 549-559. https://doi.org/10.1002/ase.1696

Ng, C. L., Liu, X., Chee, S. C., \& Ngo, R. Y. (2015). An innovative 3-dimensional model of the epitympanum for teaching of middle ear anatomy. Otolaryngology-Head and Neck Surgery, 153(5), 832-837. https://doi.org/10.1177/0194599815584600

Nguyen, N., Nelson, A. J., \& Wilson, T. D. (2012). Computer visualizations: Factors that influence spatial anatomy comprehension. Anatomical Sciences Education, 5(2), 98-108. https://doi.org/10.1002/ase.1258

Nicholson, D. T., Chalk, C., Funnell, W. R. J., \& Daniel, S. J. (2006). Can virtual reality improve anatomy education? A randomised controlled study of a computer-generated three-dimensional anatomical ear model. Medical Education, 40(11), 1081-1087. https://doi.org/10.1111/j.13652929.2006.02611.x

Pascarella, E. (2006). How college affects students: Ten directions for future research. Journal of College Student Development, 47(5), 508-520.

Rebenitsch, L., \& Owen, C. (2016). Review on cybersickness in applications and visual displays. Virtual Reality, 20(2), 101-125. https://doi.org/10.1007/s10055-016-0285-9

Roth, J. A., Wilson, T. D., \& Sandig, M. (2015). The development of a virtual 3D model of the renal corpuscle from serial histological sections for E-learning environments. Anatomical Sciences Education, 8(6), 574-583. https://doi.org/10.1002/ase.1529

Settgast, V., Pirker, J., Lontschar, S., Maggale, S., \& Gütl, C. (2016, September). Evaluating experiences in different virtual reality setups. Paper presented at the International Conference on Entertainment Computing, Vienna.

Sweller, J., Van Merrienboer, J. J., \& Paas, F. G. (1998). Cognitive architecture and instructional design. Educational Psychology Review, 10(3), 251-296.

Tan, C. T., Leong, T. W., Shen, S., Dubravs, C., \& Si, C. (2015, October). Exploring gameplay experiences on the Oculus Rift. Paper presented at the Annual Symposium on Computer-Human Interaction in Play, London.

Trelease, R. B. (2016). From chalkboard, slides, and paper to e-learning: How computing technologies have transformed anatomical sciences education. Anatomical Sciences Education, 9(6), 583-602. https://doi.org/10.1002/ase.1620

Tsaramirsis, G., Buhari, S. M., Al-Shammari, K. O., Ghazi, S., Nazmudeen, M. S., \& Tsaramirsis, K. (2016, March). Towards simulation of the classroom learning experience: Virtual reality approach. Paper presented at the 3rd International Conference on Computing for Sustainable Global Development (INDIACom), New Delhi.

von Mammen, S., Knote, A., \& Edenhofer, S. (2016, November). Cyber sick but still having fun. Paper presented at the Proceedings of the 22nd ACM Conference on Virtual Reality Software and Technology, Munich.

Wang, S. S., Xue, L., Jing, J. J., \& Wang, R. M. (2012). Virtual reality surgical anatomy of the sphenoid sinus and adjacent structures by the transnasal approach. Journal of Cranio-Maxillo-Facial Surgery, 40(6), 494-499. https://doi.org/10.1016/j.jcms.2011.08.008

Woo, Y., \& Reeves, T. C. (2007). Meaningful interaction in web-based learning: A social constructivist interpretation. The Internet and Higher Education, 10(1), 15-25. https://doi.org/http://dx.doi.org/10.1016/j.iheduc.2006.10.005

\section{Corresponding author: Christian Moro, cmoro@bond.edu.au}

Australasian Journal of Educational Technology (C) 2017.

Please cite as: Moro, C., Stromberga, Z., \& Stirling, A, (2017). Virtualisation devices for student learning: Comparison between desktop-based (Oculus Rift) and mobile-based (Gear VR) virtual reality in medical and health science education. Australasian Journal of Educational Technology, 33(6), 1-10. https://doi.org/10.14742/ajet.3840 